\title{
Carbonate mineral identification and quantification in sediment matrices using diffuse reflectance infrared Fourier transform spectroscopy
}

\author{
Rachel T. So ${ }^{1} \cdot$ Neal E. Blair ${ }^{1,2}$ (D) Andrew L. Masterson ${ }^{1}$
}

Received: 30 April 2020 / Accepted: 1 June 2020 / Published online: 16 June 2020

(c) The Author(s) 2020

\begin{abstract}
Carbonate minerals are a major reservoir in the global carbon cycle and a key player in the sequestration and emission of atmospheric $\mathrm{CO}_{2}$. In addition to the minerals' frequent use in agriculture and construction, carbonate formation has been targeted for anthropogenic $\mathrm{CO}_{2}$ sequestration. Due to carbonate's importance in geological and anthropogenic realms, research on carbonate characterization and quantification is of interest. Here, we demonstrate a method to identify and quantify calcite $\left(\mathrm{CaCO}_{3}\right)$ and dolomite $\left(\mathrm{CaMg}\left(\mathrm{CO}_{3}\right)_{2}\right)$ in sediment matrices using diffuse reflectance infrared Fourier transform spectroscopy (DRIFTS). Needing only a few minutes per sample, DRIFTS is a rapid technique that does not require hazardous chemicals and does not destroy samples during analysis. We selected the $2515 \pm 9 \mathrm{~cm}^{-1}$ absorbance bands for quantification as they exhibited little interference from sediment matrix minerals and large peak areas relative to other bands. The DRIFTS technique was compared to the traditional acidification headspace analysis method on artificial mixtures of sediment and carbonate as well as natural lake bed and river bank samples from the Upper Sangamon River Basin in Illinois, USA. DRIFTS offers an additional advantage over acidification in that it permits carbonate mineral identification simultaneously with its quantification. Though DRIFTS estimates were higher, a good correlation was found between DRIFTS and acidification estimates for both lake sediments $\left(R^{2}=0.99\right)$ and bank samples $\left(R^{2}=0.92\right)$, indicating DRIFTS is a reliable method for carbonate quantification in sediment matrices.
\end{abstract}

Keywords Carbonate quantification $\cdot$ Calcite $\cdot$ Dolomite $\cdot$ DRIFTS $\cdot$ FTIR $\cdot$ Sediments

\section{Introduction}

At 60 million Pg C, carbonate rocks are the largest carbon reservoir in Earth's lithosphere (Sharp 2007). It has a key role in long-term climate regulation as carbonate dissolution/precipitation leads to the sequestration/emission of the greenhouse gas $\mathrm{CO}_{2}$ (Berner et al. 1983). Mirroring the natural system, prominent anthropogenic carbon sequestration approaches rely on carbonate formation (Oelkers et al. 2008; Wang et al. 2020). Two of the most abundant carbonate minerals are calcite $\left(\mathrm{CaCO}_{3}\right)$ and dolomite $\left(\mathrm{MgCa}\left(\mathrm{CO}_{3}\right)_{2}\right)$,

Neal E. Blair

n-blair@northwestern.edu

1 Department of Earth and Planetary Sciences, Northwestern University, Evanston, IL 60208, USA

2 Department of Civil and Environmental Engineering, Northwestern University, Evanston, IL 60208, USA both commonly used by humans in agriculture, construction, and carbon sequestration schemes (Biasi et al. 2008; Legodi et al. 2001; Oelkers et al. 2008; Sun et al. 2014; Wang et al. 2020). Due to its prominence in the carbon cycle and in anthropogenic activities, carbonate mineral identification and quantification is a frequent need. Quantitative methods have relied on FTIR spectroscopy (Bruckman and Wriessnig 2013; Grunenwald et al. 2014; Legodi et al. 2001; Smidt et al. 2010; Tatzber et al. 2007; Vagenas et al. 2003), Raman spectroscopy (Kontoyannis and Vagenas 2000; Smith et al. 2013), X-ray powder diffraction (Bruckman and Wriessnig 2013; Kontoyannis and Vagenas 2000), and acid-released $\mathrm{CO}_{2}$ quantification (Morera-Chavarria et al. 2016; Tatzber et al. 2007).

Transmission FTIR of samples in $\mathrm{KBr}$ pellets is one of the most common methods. FTIR is rapid (a few minutes per sample), does not require hazardous chemicals, has a small sample requirement $(\sim 1 \mathrm{mg})$, and produces several distinguishable carbonate bands in its spectrum. However, it 
is challenging to be quantitative with $\mathrm{KBr}$ pellets as obtaining reproducible path lengths is difficult. Diffuse reflectance infrared Fourier transform spectroscopy (DRIFTS) is a form of FTIR with additional advantages compared to transmission FTIR. DRIFTS does not require sample dilution in infrared transparent material, thus reducing sample preparation time, its sample-holding microcells allow for fixed volumes, and the sample is recoverable after analysis.

Here, we demonstrate a method for identifying and quantifying calcite and dolomite in natural sediments using DRIFTS. Not many previous studies have used spectroscopic techniques to quantify carbonate in non-carbonate geological matrices (Bruckman and Wriessnig 2013; Du et al. 2013; Tatzber et al. 2007). As geological field samples rarely feature carbonate in its pure form, developing a reliable technique for carbonate quantification in matrices will be particularly valuable.

\section{Experimental}

\section{Field site and sample collection}

Field samples were collected from the Upper Sangamon River Basin in central Illinois, USA. This region is dominated by intensive row crop (corn and soybean) agriculture. The Sangamon watershed is part of the NSF-supported Intensively Managed Landscapes Critical Zone Observatory (IML-CZO)—established to study the impacts of long-term land use on the critical zone environment (Blair et al. 2018).

River bank samples, alluvial sediments with developing soils, were collected in 2016 from two locations along the Sangamon River: Saybrook (lat: 40.426690, lon: -88.526514), an upland portion of the watershed, and Allerton Park (lat: 39.998273, lon: - 88.650671), in the lowland floodplains (Blair et al. 2018). Bank exposures were scraped clean of external debris and sampled from the surface down to stream level. Samples were stored frozen at $-20^{\circ} \mathrm{C}$ until analysis. Likely provenances of collected samples include oxbow or lacustrine sediments, post-settlement floodplain alluvium, glacial outwash, and glacial till.

Lake bed sediment samples were collected in 2015 from Lake Decatur (lat: 39.826115, lon: - 88.924801), a reservoir at the terminus of the Upper Sangamon River Basin. The current lake is the result of a dam emplaced in 1922, and agriculturally driven erosion caused rapid filling of the lake with sediment (Blair et al. 2018). Sediment cores were obtained from the lake bed using a vibracorer. The core used in this study reached a depth of $105 \mathrm{~cm}$, estimated to be $\sim 55$ years of sediment accumulation from ${ }^{137} \mathrm{Cs}$ and ${ }^{210} \mathrm{~Pb}$ data (Blair et al. 2018). The core was subsampled at $5 \mathrm{~cm}$ intervals, and sediment from each interval was centrifuged to separate the solid phase from the pore water. Afterward, the sediment was stored frozen at $-20{ }^{\circ} \mathrm{C}$ until analysis.

Prior to FTIR analysis, all samples were lyophilized. To obtain the well-resolved and consistent spectra needed for quantification, samples were homogenized by grinding with a Crescent Wig-L-Bug ball mill for 2 min.

\section{Carbonate reference materials and standard mixtures}

Standard mixtures were prepared with agricultural calcitic lime obtained from the Alden quarry near Alden, Iowa, and dolomite purchased from Thermo Scientific Chemicals (Ward Hill, MA, USA). The identities of the carbonates were verified through analysis of the $877 \pm 6 \mathrm{~cm}^{-1}$ and $721 \pm 9 \mathrm{~cm}^{-1}$ carbonate bands in their DRIFTS spectra for which Pezzolo (2013) reported peak wavenumbers for calcite at $877 \mathrm{~cm}^{-1}$ and $713 \mathrm{~cm}^{-1}$, and dolomite at $883 \mathrm{~cm}^{-1}$ and $729 \mathrm{~cm}^{-1}$. Four sets of calibration standards were made, two with calcite and two with dolomite. Standards were mixtures of known carbonate quantities (calcite or dolomite) and lyophilized, low-carbonate Lake Decatur sediment (initially thought to be carbonate-free from the absence of a peak complex in the $2515 \pm 9 \mathrm{~cm}^{-1}$ spectral region, but headspace analysis of acidified samples recorded $0.24 \pm 0.1 \mathrm{wt} \%$ carbonate). Two sets of standard mixtures (one calcite, one dolomite) spanned $0-40 \mathrm{wt} \%$ carbonate at $5 \%$ intervals. The other two spanned $0-5 \%$ at $1 \%$ intervals. All mixtures were milled for homogeneity.

\section{Carbonate quantification by DRIFTS}

Absorbance DRIFTS spectra were recorded using a Bruker Tensor 37 FTIR spectrometer with a Harrick Praying Mantis DRIFTS attachment. Each spectrum was recorded from 4000 to $400 \mathrm{~cm}^{-1}$ with a $4 \mathrm{~cm}^{-1}$ resolution and an average of 16 scans. All spectra were corrected against a $\mathrm{KBr}$ background. A 3-mm-diameter sampling cup capable of holding $~ 30 \mathrm{mg}$ of sample was used. Samples were gently tamped down into the cup, and the sample surface was leveled to the cup rim. A minimum of two spectra were recorded per sample.

Each spectrum was analyzed using the OPUS Quant 6.5 software (Bruker Optics). Due to the different shapes and wavenumber ranges for the $2515 \pm 9 \mathrm{~cm}^{-1}$ bands of calcite and dolomite, different calibrations were needed for each mineral. For samples with more than 5\% carbonate, the peak complex was integrated from 2647 to $2452 \mathrm{~cm}^{-1}$ for calcite and 2679 to $2455 \mathrm{~cm}^{-1}$ for dolomite. For samples with less than 5\% carbonate, it was integrated from 2637 to $2466 \mathrm{~cm}^{-1}$ for calcite and 2662 to $2468 \mathrm{~cm}^{-1}$ for dolomite. The integration baseline is a line connecting the left and right edges of the peak between the wavenumbers to be integrated. 


\section{Carbonate quantification by acidification}

Carbonate concentrations measured with DRIFTS were compared to estimates made via headspace analyses of acidified samples using a Thermo Scientific GasBench II coupled to a Thermo Scientific Delta V Isotope Ratio Mass Spectrometer. Samples were reacted with anhydrous (103\%) phosphoric acid $\left(\mathrm{H}_{3} \mathrm{PO}_{4}\right)$ for $6 \mathrm{~h}$ at $70{ }^{\circ} \mathrm{C}$. The instrument was calibrated and analytical uncertainty estimated with the international calcite standards NBS 18 and NBS 19. The precision of the carbonate concentration measurements is $\pm 0.1 \mathrm{wt} \%$.

\section{Results and discussion}

\section{Carbonate in the DRIFTS spectrum}

Carbonate bands with potential for quantification were identified in the $2515 \pm 9 \mathrm{~cm}^{-1}, 1805 \pm 9 \mathrm{~cm}^{-1}, 877 \pm 6 \mathrm{~cm}^{-1}$, and $721 \pm 9 \mathrm{~cm}^{-1}$ spectral regions of the DRIFTS spectra (Fig. 1a). A peak or peak complex at these regions suggests carbonate presence with the exact peak wavenumbers varying by carbonate mineral. For the $1805 \pm 9 \mathrm{~cm}^{-1}$, $877 \pm 6 \mathrm{~cm}^{-1}$, and $721 \pm 9 \mathrm{~cm}^{-1}$ regions, calcite had peaks at $1796 \mathrm{~cm}^{-1}, 875 \mathrm{~cm}^{-1}$, and $712 \mathrm{~cm}^{-1}$, while dolomite had peaks at $1814 \mathrm{~cm}^{-1}, 880 \mathrm{~cm}^{-1}$, and $730 \mathrm{~cm}^{-1}$. For both minerals, peak complexes were observed in the $2515 \pm 9 \mathrm{~cm}^{-1}$ region. The maximum peak of calcite is at $2516 \mathrm{~cm}^{-1}$ with a shoulder at $2600 \mathrm{~cm}^{-1}$, while that of dolomite occurs at $2523 \mathrm{~cm}^{-1}$ with a smaller shouldering peak at $2625 \mathrm{~cm}^{-1}$ (Fig. 1b). Calibrations were explored for all four spectral regions. The statistical performance of all $0-40 \%$ calibrations was similar (most $R^{2}>0.95$, and slope and intercept $p<0.05$ ), but not the 0-5\% calibrations. For both minerals, the $1805 \pm 9 \mathrm{~cm}^{-1}, 877 \pm 6 \mathrm{~cm}^{-1}$, and $721 \pm 9 \mathrm{~cm}^{-1}$ bands had small peak areas or peak overlaps from matrix interference, likely reducing $R^{2}$ for some calibrations. Because the $2515 \pm 9 \mathrm{~cm}^{-1}$ bands appeared in a region without peak overlaps, had the largest integration areas, and resulted in high $R^{2}$ values, they were selected for DRIFTS calibration.

\section{Calibration for carbonate quantification}

Figure 2a shows the relation between spectral peak integration area and carbonate concentration for the $0-40 \%$ calcite and dolomite calibration mixtures (both $R^{2}=0.99$ ). Figure $2 \mathrm{~b}$ shows the same for the $0-5 \%$ mixtures (both $R^{2}=0.97$ ). All calibrations had slope and intercept $p<0.05$ except for the dolomite $0-40 \%$ calibration (intercept $p=0.93$ ).

In this study, we have focused on single-carbonate minerals within a sediment matrix. We acknowledge it is possible for geological samples to contain a mix of
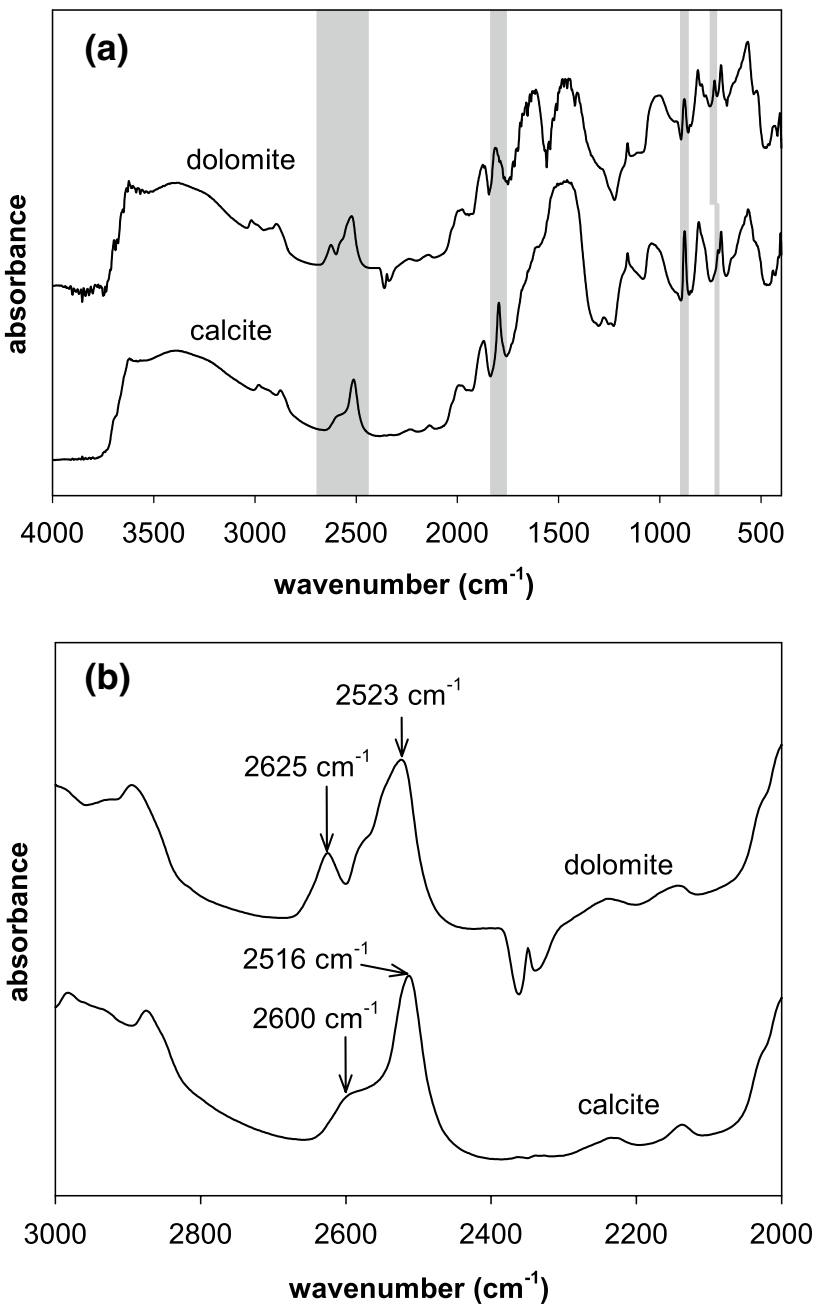

Fig. 1 Diffuse reflectance infrared Fourier transform spectroscopy (DRIFTS) was performed on carbonate-sediment mixtures by the analysis of internally reflected incident infrared light from powdered samples. a DRIFTS spectra of the $25 \%$ calcite and the $25 \%$ dolomite calibration standard mixtures. Shaded boxes indicate regions with carbonate bands considered for calibration. Single peaks were observed at $1805 \pm 9 \mathrm{~cm}^{-1}, 877 \pm 6 \mathrm{~cm}^{-1}$, and $721 \pm 9 \mathrm{~cm}^{-1}$, and peak complexes at $2515 \pm 9 \mathrm{~cm}^{-1}$. b $2515 \pm 9 \mathrm{~cm}^{-1}$ carbonate bands of the 1a spectra

carbonate minerals. To our knowledge, only one study has attempted to quantify mixtures of different carbonate minerals within a matrix (Bruckman and Wriessnig 2013). However, it required two different methods, transmission FTIR and powder X-ray diffraction, and relied on the latter to distinguish different minerals. The DRIFTS approach alone should be able to resolve and quantify carbonates in such samples. The redundancy offered by multiple bands provides a means to avoid matrix interference, and the overlapping peak complexes at $2515 \pm 9 \mathrm{~cm}^{-1}$ can be deconvoluted and deconvoluted peaks characteristic of different carbonates can be used for calibration. As the field samples in this study did not contain mixtures of different 

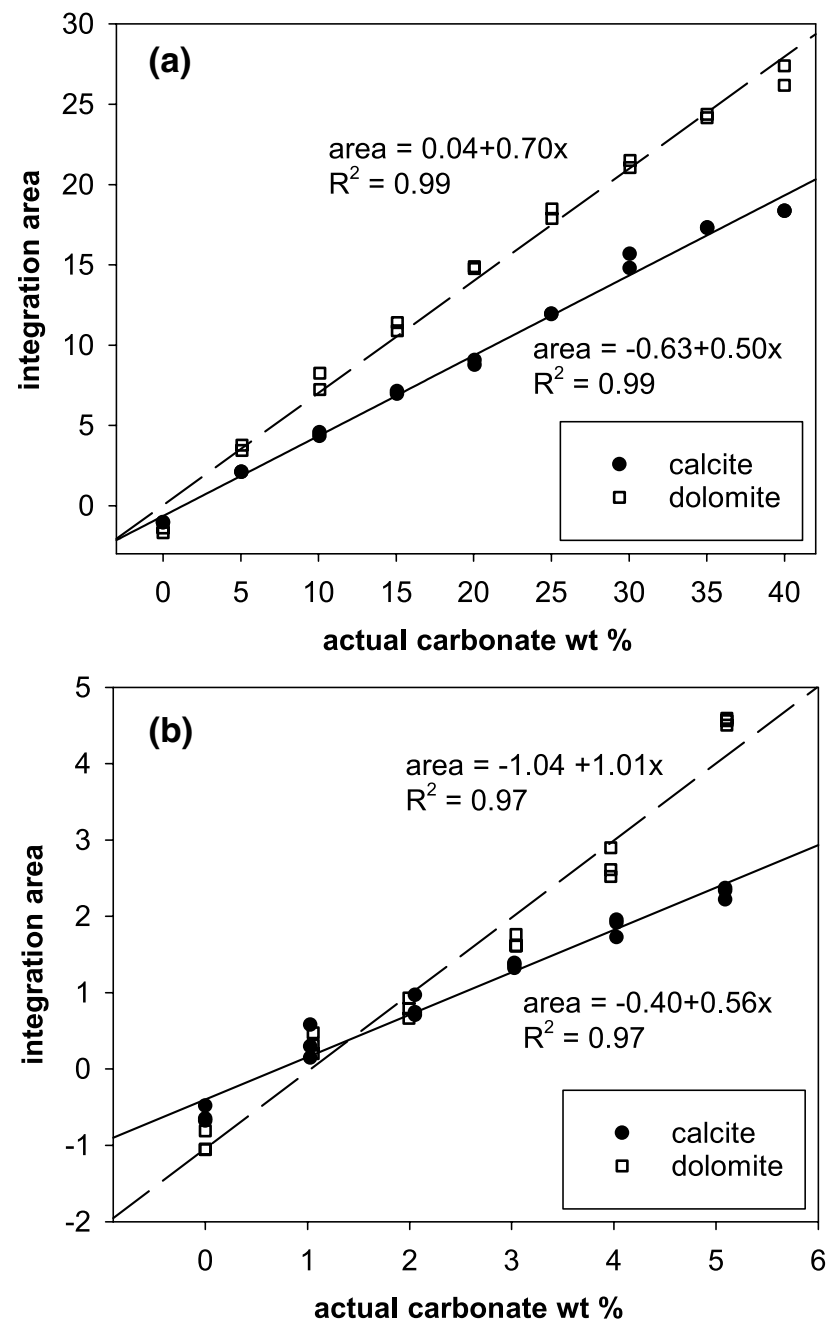

Fig. 2 Calibration curves for quantifying calcite and dolomite using the $2515 \pm 9 \mathrm{~cm}^{-1}$ carbonate bands for a $0-40 \%$ standard mixtures, and b $0-5 \%$ standard mixtures. Both $0-40 \%$ calibrations had $R^{2}=0.99$, and both $0-5 \%$ calibrations had $R^{2}=0.97$. In both cases, the dolomite calibration had a steeper slope, indicating a larger peak area for the same carbonate wt $\%$ compared to calcite

carbonate minerals, single-carbonate calibrations were sufficient.

\section{Comparison of DRIFTS and acidification estimates}

Analysis of peak wavenumbers in the $2515 \pm 9 \mathrm{~cm}^{-1}$, $877 \pm 6 \mathrm{~cm}^{-1}$, and $721 \pm 9 \mathrm{~cm}^{-1}$ bands indicated Lake Decatur contained only calcite, while Sangamon bank samples contained only dolomite (Table 1). In lake sediments, acidification estimates commonly fell below DRIFTS estimates, with larger differences for samples with higher calcite contents. On average, DRIFTS estimates were 1.26 times higher than acidification. Tatzber et al. (2007) found a similar result when comparing calcite estimates made through transmission FTIR and $\mathrm{HCl}$ acidification, the former having estimates 1.56 that of the latter. The same trend appeared in bank samples with DRIFTS estimates being 1.09 times higher on average.

It is notable that the DRIFTS-acidification discrepancy appears only for field samples, not calibration mixtures (Table 1). Longer sample incubation periods in the GasBench (48 h, data not shown) did not remove the discrepancy suggesting acidification reaction times were not the issue. That calibration mixtures had similar DRIFTS and acidification estimates also suggests instrumental calibrations were not the issue. Two possible explanations are a matrix effect (wherein interactions between the carbonate and matrix in field samples resulted in an incomplete acidification reaction) or a physical difference between calibration standard carbonates and field sample carbonates. Despite the discrepancy, the two sets of estimates had a good correlation (Fig. 3). Lake Decatur samples had $R^{2}=0.99$ (slope and intercept $p<<0.05$ ), while Sangamon bank samples had $R^{2}=0.92$ (slope $p<<0.05$, intercept $p=0.05$ ).

\section{Conclusion}

Carbonate mineral analysis, once primarily the purview of geological studies, has gained a new importance due to efforts to artificially sequester carbon for climate control. Rapid, nondestructive analytical methods requiring modest sample preparation and providing qualitative and quantitative information would be of value. The proposed DRIFTS method can both identify and quantify calcite and dolomite minerals in sediment matrices using multiple spectral regions. The $2515 \pm 9 \mathrm{~cm}^{-1}$ spectral window shows promise for quantification in samples where matrix interference may preclude the use of other bands. Though field sample DRIFTS estimates systematically differed from acidification estimates, the good correlation between the two methods $\left(R^{2}=0.99\right.$ for Lake Decatur sediments, $R^{2}=0.92$ for Sangamon bank samples) suggests DRIFTS is a reliable method for quantifying calcite and dolomite in sediment matrices. 
Table 1 Carbonate contents of select calibration standards and field samples from the Upper Sangamon River Basin

\begin{tabular}{|c|c|c|c|c|}
\hline \multirow[t]{2}{*}{ Sample ID } & \multirow[t]{2}{*}{ Carbonate mineral } & \multicolumn{2}{|c|}{ Estimated carbonate content } & \multirow{2}{*}{$\begin{array}{l}\text { Actual } \\
\text { carbonate } \\
\text { content } \\
\text { Mass (wt \%) }\end{array}$} \\
\hline & & DRIFTS (wt\%) & $\begin{array}{l}\text { Acidifica- } \\
\text { tion (wt } \%)\end{array}$ & \\
\hline \multicolumn{5}{|l|}{ Calibration standard mixtures } \\
\hline CCS $25 \%$ & Calcite & 25.15 & 24.00 & 25.00 \\
\hline CCS $40 \%$ & Calcite & 37.92 & 40.75 & 40.01 \\
\hline DCS $5 \%$ & Dolomite & 5.25 & 5.34 & 5.07 \\
\hline DCS $25 \%$ & Dolomite & 25.93 & 26.82 & 25.03 \\
\hline DCS $40 \%$ & Dolomite & 38.13 & 39.96 & 40.00 \\
\hline \multicolumn{5}{|l|}{ Lake Decatur core } \\
\hline LDC $0-5 \mathrm{~cm}$ & Calcite & 11.95 & 8.13 & \\
\hline LDC 5-10 cm & Calcite & 15.30 & 11.19 & \\
\hline LDC $10-15 \mathrm{~cm}$ & Calcite & 19.62 & 14.94 & \\
\hline LDC $15-20 \mathrm{~cm}$ & Calcite & 19.76 & 15.32 & \\
\hline LDC $20-25 \mathrm{~cm}$ & Calcite & 18.75 & 13.79 & \\
\hline LDC $25-30 \mathrm{~cm}$ & Calcite & 18.48 & 13.63 & \\
\hline LDC $30-35 \mathrm{~cm}$ & Calcite & 18.36 & 13.10 & \\
\hline LDC $40-45 \mathrm{~cm}$ & Calcite & 12.43 & 9.32 & \\
\hline $\mathrm{LDC} 45-50 \mathrm{~cm}$ & Calcite & 10.98 & 8.38 & \\
\hline LDC $50-55 \mathrm{~cm}$ & Calcite & 8.94 & 6.80 & \\
\hline LDC $55-60 \mathrm{~cm}$ & Calcite & 5.54 & 4.70 & \\
\hline LDC $60-65 \mathrm{~cm}$ & Calcite & 10.08 & 8.19 & \\
\hline LDC $65-70 \mathrm{~cm}$ & Calcite & 10.35 & 7.92 & \\
\hline LDC $70-75 \mathrm{~cm}$ & Calcite & 9.03 & 6.79 & \\
\hline LDC $75-80 \mathrm{~cm}$ & Calcite & 4.12 & 4.30 & \\
\hline LDC $80-85 \mathrm{~cm}$ & Calcite & 3.42 & 3.53 & \\
\hline LDC 85-90 cm & Calcite & 6.69 & 5.86 & \\
\hline LDC 90-95 cm & Calcite & 8.63 & 7.47 & \\
\hline LDC $95-100 \mathrm{~cm}$ & Calcite & 9.54 & 7.65 & \\
\hline LDC $100-105 \mathrm{~cm}$ & Calcite & 9.36 & 7.72 & \\
\hline \multicolumn{5}{|l|}{ Sangamon bank samples } \\
\hline AP $151030-1,0-5 \mathrm{~cm}$ & Dolomite & 0.60 & 0.90 & \\
\hline AP 151030-4, mud drape & Dolomite & 2.79 & 2.90 & \\
\hline SB8 151030-1, 0-5 cm & Dolomite & 7.89 & 8.30 & \\
\hline SB8 $151030-2,25-30 \mathrm{~cm}$ & Dolomite & 5.43 & 5.14 & \\
\hline SB8 151030-3, 40-45 cm & Dolomite & 17.74 & 16.21 & \\
\hline SB8 151030-4, 70-75 cm & Dolomite & 8.19 & 7.90 & \\
\hline SB8 151030-5, 95-100 cm & Dolomite & 7.45 & 5.80 & \\
\hline SB8 151030-6, 113-118 cm & Dolomite & 9.96 & 6.91 & \\
\hline SB10 151030-5, 250-255 cm & Dolomite & 25.55 & 16.48 & \\
\hline SB11 151030-2, 50-55 cm & Dolomite & 3.62 & 3.96 & \\
\hline SB11 151030-3, 65-70 cm & Dolomite & 6.49 & 6.37 & \\
\hline
\end{tabular}

LDC samples had 3-20\% calcite with shallower samples occupying the higher end of the range. SB and AP samples had 0-25\% dolomite

$C C S$ calcite calibration standard, DCS dolomite calibration standard, $L D C$ Lake Decatur core, AP Allerton Park, $S B$ Saybrook 


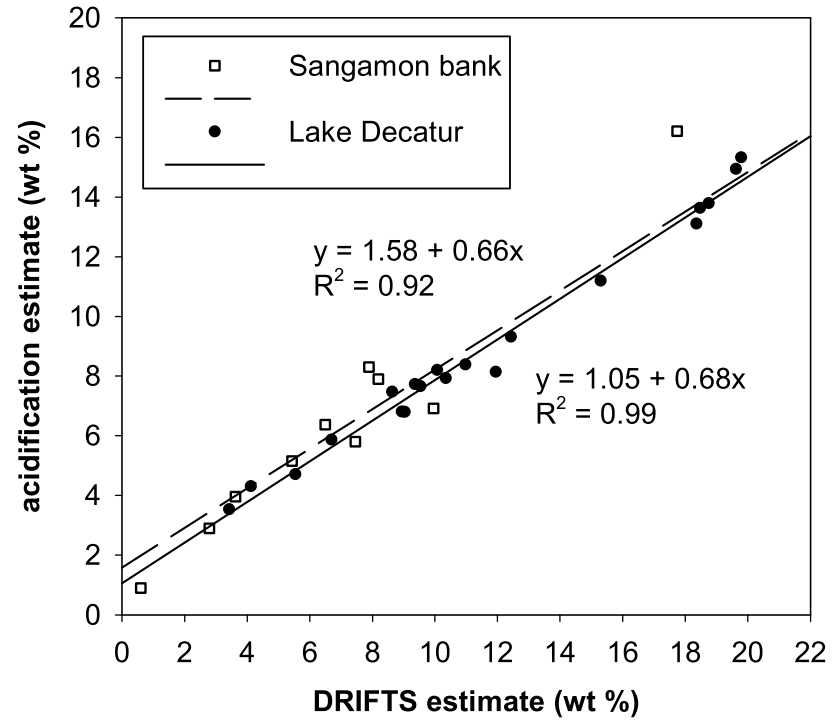

Fig. 3 Correlation between DRIFTS and acidification estimates for Lake Decatur sediments (calcite) and Sangamon bank samples (dolomite). Both correlation lines are very similar indicating similar degrees of DRIFTS-acidification discrepancies for all samples. DRIFTS: Diffuse reflectance infrared Fourier transform spectroscopy

Acknowledgements Financial support was provided by the U.S. National Science Foundation (NSF) Grant \# EAR-1331906 for the Critical Zone Observatory for Intensively Managed Landscapes (IMLCZO), a multi-institutional collaborative effort. Support was also provided by Northwestern University's Undergraduate Research Grant program. We thank the IML-CZO team members who have contributed to the project in the forms of field assistance, advice, sample collection, and analyses. Special thanks go to Andrew Stumpf for his guidance with the river bank sampling and Doug Schnoebelen for assistance with the vibracoring.

Open Access This article is licensed under a Creative Commons Attribution 4.0 International License, which permits use, sharing, adaptation, distribution and reproduction in any medium or format, as long as you give appropriate credit to the original author(s) and the source, provide a link to the Creative Commons licence, and indicate if changes were made. The images or other third party material in this article are included in the article's Creative Commons licence, unless indicated otherwise in a credit line to the material. If material is not included in the article's Creative Commons licence and your intended use is not permitted by statutory regulation or exceeds the permitted use, you will need to obtain permission directly from the copyright holder. To view a copy of this licence, visit http://creativecommons.org/licenses/by/4.0/.

\section{References}

Berner RA, Lasaga AC, Garrels RM (1983) The carbonate-silicate geochemical cycle and its effect on atmospheric carbon-dioxide over the past 100 million years. Am J Sci 283:641-683. https:// doi.org/10.2475/ajs.283.7.641
Biasi C, Lind SE, Pekkarinen NM et al (2008) Direct experimental evidence for the contribution of lime to $\mathrm{CO}_{2}$ release from managed peat soil. Soil Biol Biochem 40:2660-2669. https://doi. org/10.1016/j.soilbio.2008.07.011

Blair NE, Leithold EL, Papanicolaou ANT et al (2018) The C-biogeochemistry of a Midwestern USA agricultural impoundment in context: Lake Decatur in the intensively managed landscape critical zone observatory. Biogeochemistry 138:171-195. https ://doi.org/10.1007/s10533-018-0439-9

Bruckman VJ, Wriessnig K (2013) Improved soil carbonate determination by FT-IR and X-ray analysis. Environ Chem Lett 11:65-70. https://doi.org/10.1007/s10311-012-0380-4

Du CW, Ma ZY, Zhou JM et al (2013) Application of mid-infrared photoacoustic spectroscopy in monitoring carbonate content in soils. Sens Actuator B Chem 188:1167-1175. https://doi.org/10.1016/j. snb.2013.08.023

Grunenwald A, Keyser C, Sautereau AM et al (2014) Revisiting carbonate quantification in apatite (bio)minerals: a validated FTIR methodology. J Archaeol Sci 49:134-141. https://doi. org/10.1016/j.jas.2014.05.004

Kontoyannis CG, Vagenas NV (2000) Calcium carbonate phase analysis using XRD and FT-Raman spectroscopy. Analyst 125:251255. https://doi.org/10.1039/a908609i

Legodi MA, de Waal D, Potgieter JH et al (2001) Rapid determination of $\mathrm{CaCO}_{3}$ in mixtures utilising FT-IR spectroscopy. Miner Eng 14:1107-1111. https://doi.org/10.1016/s0892-6875(01)00116-9

Morera-Chavarria A, Griffioen J, Behrends T (2016) Optimized sequential extraction for carbonates: quantification and delta C-13 analysis of calcite, dolomite and siderite. Chem Geol 443:146157. https://doi.org/10.1016/j.chemgeo.2016.09.025

Oelkers EH, Gislason SR, Matter J (2008) Mineral carbonation of $\mathrm{CO}_{2}$. Elements 4:333-337. https://doi.org/10.2113/gselements.4.5.333

Pezzolo AD (2013) An exercise on calibration: DRIFTS study of binary mixtures of calcite and dolomite with partially overlapping spectral features. J Chem Educ 90:118-122. https://doi.org/10.1021/ ed2008729

Sharp Z (2007) Principles of stable isotope geochemistry, 2nd edn. https://doi.org/10.25844/h9q1-0p82

Smidt E, Meissl K, Tintner J et al (2010) Interferences of carbonate quantification in municipal solid waste incinerator bottom ash: evaluation of different methods. Environ Chem Lett 8:217-222. https://doi.org/10.1007/s10311-009-0209-y

Smith GPS, Gordon KC, Holroyd SE (2013) Raman spectroscopic quantification of calcium carbonate in spiked milk powder samples. Vib Spectrosc 67:87-91. https://doi.org/10.1016/j.vibsp ec.2013.04.005

Sun JM, Wu ZG, Cheng HF et al (2014) A Raman spectroscopic comparison of calcite and dolomite. Spectrochim Acta Part A Molec Biomol Spectrosc 117:158-162. https://doi.org/10.1016/j. saa.2013.08.014

Tatzber M, Stemmer M, Spiegel H et al (2007) An alternative method to measure carbonate in soils by FT-IR spectroscopy. Environ Chem Lett 5:9-12. https://doi.org/10.1007/s10311-006-0079-5

Vagenas NV, Gatsouli A, Kontoyannis CG (2003) Quantitative analysis of synthetic calcium carbonate polymorphs using FT-IR spectroscopy. Talanta 59:831-836. https://doi.org/10.1016/s0039 -9140(02)00638-0

Wang B, Pan ZH, Cheng HG et al (2020) $\mathrm{CO}_{2}$ sequestration: high conversion of gypsum into $\mathrm{CaCO}_{3}$ by ultrasonic carbonation. Environ Chem Lett. https://doi.org/10.1007/s10311-020-00997-9

Publisher's Note Springer Nature remains neutral with regard to jurisdictional claims in published maps and institutional affiliations. 